\title{
Abnormal Asymmetry in Language Association Cortex in Autism
}

Martha R. Herbert, MD, PhD, ${ }^{1}$ Gordon J. Harris, PhD, ${ }^{2}$ Kristen T. Adrien, BA, ${ }^{1}$ David A. Ziegler, BS, ${ }^{1}$ Nikos Makris, MD, PhD, ${ }^{1}$ Dave N. Kennedy, $\mathrm{PhD},{ }^{1}$ Nicholas T. Lange, PhD, ${ }^{3}$ Chris F. Chabris, PhD, ${ }^{2}$ Anna Bakardjiev, MD, ${ }^{5}$ James Hodgson, PhD, ${ }^{6}$ Masanori Takeoka, MD, ${ }^{7}$ Helen Tager-Flusberg, PhD, ${ }^{4}$ and Verne S. Caviness, Jr., MD ${ }^{1}$

\begin{abstract}
Autism is a neurodevelopmental disorder affecting cognitive, language, and social functioning. Although language and social communication abnormalities are characteristic, prior structural imaging studies have not examined languagerelated cortex in autistic and control subjects. Subjects included 16 boys with autism (aged 7-11 years), with nonverbal IQ greater than 80, and 15 age- and handedness-matched controls. Magnetic resonance brain images were segmented into gray and white matter; cerebral cortex was parcellated into $\mathbf{4 8}$ gyral-based divisions per hemisphere. Asymmetry was assessed a priori in language-related inferior lateral frontal and posterior superior temporal regions and assessed post hoc in all regions to determine specificity of asymmetry abnormalities. Boys with autism had significant asymmetry reversal in frontal language-related cortex: $27 \%$ larger on the right in autism and $17 \%$ larger on the left in controls. Only one additional region had significant asymmetry differences on post hoc analysis: posterior temporal fusiform gyrus (more left-sided in autism), whereas adjacent fusiform gyrus and temporooccipital inferior temporal gyrus both approached significance (more right-sided in autism). These inferior temporal regions are involved in visual face processing. In boys with autism, language and social/face processing-related regions displayed abnormal asymmetry. These structural abnormalities may relate to language and social disturbances observed in autism.
\end{abstract}

Ann Neurol 2002;52:588-596

Autistic individuals are impaired in their ability to interact appropriately with others through deficits in language, communication, and social skills. ${ }^{1}$ However, structural imaging studies of autism to date have not focused on brain structural measures in regions specifically related to language. ${ }^{2}$ Many imaging studies in autism have had limitations in sample selection or imaging methods, and focal defects reported in some studies have not been consistently replicated by other groups. ${ }^{3,4}$ For example, imaging studies of brain structure in subjects with autism that have focused on ventricular, subcortical, and cerebellar sizes have not demonstrated a consistent pattern of brain abnormality. ${ }^{5-9}$ However, one common observation in autism studies is that some autistic subjects have increased head and brain size. ${ }^{10-16}$

Language is an especially pertinent domain with which to begin to relate brain structure to autism clinical features. Language is central to both diagnosis and prognosis in autism. ${ }^{17}$ Furthermore, there is evidence that a subpopulation of children with autism share language features parallel to those observed in specific language impairment $(\mathrm{SLI})^{18}$ and genetic studies in delayed language autistic subjects who have siblings with language delay point to linkage in the same gene region identified in SLI. ${ }^{19-24}$ Thus, subjects with autism who display language disorders and SLI subjects may represent partially overlapping populations. Several magnetic resonance imaging (MRI) studies of brain structure in subjects with SLI have demonstrated abnormal asymmetry patterns in frontal and temporal lobe regions related to language function. ${ }^{25-32}$ Whereas in key language areas in normal individuals there is a bias toward larger cortical regions in the left hemisphere, the reverse pattern has been found in several studies of children and adults with SLI or language-based learning disorders. Thus, in this study, we hypothesized that language regions of the frontal and temporal lobes also may show abnormal asymmetry patterns in autistic subjects.
From the ${ }^{1}$ Center for Morphometric Analysis and ${ }^{2}$ Radiology Computer Aided Diagnostics Laboratory, Massachusetts General Hospital, Boston; ${ }^{3}$ McLean Hospital Brain Imaging Center, Belmont; ${ }^{4}$ Boston University School of Medicine, Boston, MA; ${ }^{5}$ Children's Hospital, Oakland, CA; ${ }^{6}$ Pennington School, Pennington, NJ; and ${ }^{7}$ Keio University School of Medicine, Tokyo, Japan.

Received Feb 4, 2002, and in revised form May 29. Accepted for publication Jun 29, 2002.
Address correspondence to Dr Herbert, Center for Morphometric Analysis, Massachusetts General Hospital, CNY-149, Room 6012, Boston, MA 02114. E-mail mherbert1@partners.org 
Several cortical language-processing areas are fairly well defined and large enough to be studied using morphometric imaging methods. We evaluated brain structure using MRI in hypothesis-driven, a priori languagelinked heteromodal association cortical regions: specifically, inferior lateral prefrontal pars opercularis (related to Broca's region) and posterior superior temporal gyrus (related to Wernicke's area) and interconnected cortical regions functionally related to these language association centers, including inferior frontal pars triangularis, frontal operculum, angular gyrus, supramarginal gyrus, planum temporale, and parietal operculum. The cortical parcellation methodology applied in this study, by allowing the discrimination of language-related cortical regions, enables an important next step in the evolution of neuroimaging studies of autism.

The aim of this study is to assess cerebral cortex brain morphometry, particularly in cortical regions associated with language function, in a well-characterized group of children with autism. We assessed, through quantitative neuroimaging segmentation and cortical parcellation analysis, the regional cortical volume asymmetry patterns in boys with autism and compared these measures with those in normal control boys. To our knowledge, no prior structural imaging study has examined language-related cortical regions in autistic subjects.

\section{Subjects and Methods \\ Subjects}

Included in this study were 16 boys with autism $(9.0 \pm 1.2$; range, $7-11$ years) and 15 normal control boys $(8.3 \pm 2.0$; range, 7-11 years). Subjects did not differ on handedness (control: one left-handed, one mixed dominant; all other subjects right-handed), and the two groups were age matched. All boys with autism had performance IQ greater than 80 . The control subjects were recruited specifically to the imaging arm of the study and were eligible if they had normal school performance and developmental history without seizures or significant head injury, and if their neurological examinations were normal. The boys with autism were recruited by clinical referral or by participation in school special needs programs as part of a large National Institute of Neurological Disorders and Stroke-funded multicenter study of language and communication impairment in preschool children. ${ }^{10}$ Girls were excluded from this study because the imaged sample included only two autistic girls with IQ greater than 80 . The control boys were recruited for the imaging arm of a follow-up study in the primary school years. All subjects were imaged after informed written consent was obtained, and none required sedation. The control boys ${ }^{33}$ have been included in prior imaging reports of normal brain structure. English as the primary language was required of all subjects and their families. Subjects were excluded if they had hearing or gross sensorimotor deficits, clinical evidence of progressive encephalopathy, frequent seizures, high doses of anticonvulsant drugs or psychotropic medication, the presence of potentially paramagnetic metals and overtly evident focal brain lesions, brain atrophy, or ventriculomegaly.

The subjects with autism were recruited before they entered school as part of a larger study of children with inadequate communication. ${ }^{10}$ State-of-the-art diagnostic instruments available at the time the study was conducted were used for classification, and expert clinicians confirmed all diagnoses. All candidates for the autism group were screened using the three-part Wing Autistic Disorder Interview Checklist (WADIC). ${ }^{10}$ This test involved a parent questionnaire reviewed with an investigator or trained research assistant that covered (1) impairment in social relatedness (nine questions), (2) impairment in social communication (five questions), and (3) restricted or repetitive activities (seven questions). If the child either (1) met at least one criterion from each of three sections of the WADIC, or (2) met two criteria from the first section of this interview checklist, then the child was provisionally classified as possibly autistic. Absolute criteria from the WADIC screen for inclusion in the autistic group comprised meeting three criteria in the first set, three in the second, and one in the third. All diagnoses were confirmed by a blinded child psychiatrist who performed a structured comprehensive evaluation with determination of diagnosis according to Diagnostic and Statistical Manual of Mental Disorders (DSM) III-R criteria that were current at the time of data acquisition. All subjects satisfied DSM III-R criteria for autistic disorder at the time they were diagnosed.

\section{Image Acquisition and Analysis}

MRI was performed on either General Electric 1.5T Signa (Milwaukee, WI) or Siemens 1.5T (Iselin, NJ) MRI systems. The scanner platform had changed during the study acquisition period. Although it was suboptimal that the scanner platform changed, several steps were taken to minimize any adverse impact on the study. Specifically, reliability of measurements was tested and confirmed between scanners before continuing on the new platform. ${ }^{34}$ To further ensure that the use of multiple imaging systems was not a confounding factor in this study, all statistical analyses included scanner type as a covariate.

Image acquisitions included a T1-weighted sagittal scout series, a coronal T2-weighted sequence, to rule out overt focal lesions, atrophy, or ventriculomegaly, and a coronal volumetric T1-weighted spoiled gradient echo-imaging sequence for the morphometric analysis. When performed on GE systems, the following parameters were used for the volumetric acquisition: pulse sequence $=3 \mathrm{D}-\mathrm{SPGR}$ or $3 \mathrm{D}$-CAPRY; $\mathrm{TR}=34$ to 50 milliseconds; $\mathrm{TE}=5$ to 9 milliseconds; flip angle $=45$ to 50 degrees; field of view $=24$ to $26 \mathrm{~cm}$; slice thickness $=3.0$ to $3.1 \mathrm{~mm}$; number of slices $=60$ contiguous; matrix $=256 \times 256$; and number of excitations $=1$. On Siemens systems, the following parameters were used for the volumetric acquisition: pulse sequence $=3 \mathrm{D}$-FLASH; $\mathrm{TR}=40$ milliseconds; $\mathrm{TE}=10$ milliseconds; flip angle $=$ 40 degrees; field of view $=30 \mathrm{~cm}$; slice thickness $=3.1 \mathrm{~mm}$; number of slices $=60$ contiguous; matrix $=256 \times 256$; number of excitations $=1$.

The imaging data sets were processed on a computer workstation with custom software. Head position was nor- 
malized by reslicing each volume with $3 \mathrm{~mm}$ thickness along the coronal plane perpendicular to the anterior commissureposterior commissure plane, without scaling the image size.

Image signal intensity gradients caused by MR field inhomogeneity were corrected before segmentation. ${ }^{35}$ Neuroanatomic segmentation of gray and white matter and ventricles was performed using semiautomated procedures based on intensity contour mapping and differential intensity contour algorithms previously described. ${ }^{33,36-38}$

The neocortical ribbon then was parcellated into 48 primarily gyral-based parcellation units per hemisphere, according to a three-step procedure previously described. ${ }^{33,39}$ Briefly, sulcal patterns were identified and labeled on multiplanar orthogonal views by a neuroanatomically trained rater, and the sulcal markers were tracked three-dimensionally as borders between cortical parcellation units. These regions then were defined and identified by a color-coding system, the voxels were summed, and recorded quantitatively to indicate the gray matter volume of each cortical parcellation unit. White matter was not included in these cortical measurements. Cortical parcellation units and the naming convention legend are presented in Table 1.

Comparisons between volumes in parcellation regions in the left $(\mathrm{L})$ and right $(\mathrm{R})$ hemispheres were expressed as a symmetry index. ${ }^{40}$ This was calculated for each structure in each brain as $2^{*}(\mathrm{~L}-\mathrm{R}) /(\mathrm{L}+\mathrm{R})$, and then multiplied by 100 to provide a percentage value. Positive symmetry index values indicate that the region is larger in the left hemisphere than in the right.

Our hypothesis was that language-related association cortices of the frontal and temporal lobes would demonstrate structural abnormalities in subjects with autism. Broca's region centers on inferior lateral frontal pars opercularis (F3o in Fig) and is also linked with adjacent frontal regions including inferior lateral frontal pars triangularis ( $\mathrm{F} 3 \mathrm{t})$, frontal operculum (FO), and insula (INS). Wernicke's region centers on posterior superior temporal gyrus (T1p). Adjacent temporal and parietal regions also functionally linked with Wernicke's area include angular gyrus (AG), supramarginal gyrus (SGa, SGp), planum temporale (PT), and parietal operculum (PO). These regions were selected as the frontal and temporal lobe a priori hypothesis-driven language-related regions based on prior parcellation studies of language localization. ${ }^{41,42}$

The symmetry index values in these a priori hypothesisdriven language regions were compared between the boys with autism and the control boys using a multivariate general linear model (GLM) program (SPSS statistical software, Chicago, IL). The GLM analysis for the language regions accounts for multiple comparisons, and if the GLM model indicates significant overall differences in the Wilks $\lambda$ multivariate test, then each measure within the model can be assessed for group differences without additional adjustment for multiple comparisons. To control for possible confounding effects of age and scanner, we included these variables as covariates in the model. Additional GLM analyses were run to explore the possibility that differences exist between autistic and control children in all remaining brain regions not included in the a priori analyses. Because these post hoc analyses were exploratory in nature, intended to evaluate the
Table 1. Cortical Parcellation Units with Abbreviations

\begin{tabular}{|c|c|}
\hline Abbreviation & Meaning \\
\hline$A G$ & Angular gyrus \\
\hline CALC & Intracalcarine cortex \\
\hline $\mathrm{CGa}$ & Cingulate gyrus, anterior \\
\hline CGp & Cingulate gyrus, posterior \\
\hline $\mathrm{CN}$ & Cuneal cortex \\
\hline $\mathrm{CO}$ & Central operculum \\
\hline $\mathrm{F} 1$ & Superior frontal gyrus \\
\hline $\mathrm{F} 2$ & Middle frontal 2 gyrus \\
\hline F3o & Inferior frontal 3 gyrus, pars opercularis \\
\hline $\mathrm{F} 3 \mathrm{t}$ & Inferior frontal 3 gyrus, pars triangularis \\
\hline FMC & Frontal medial cortex \\
\hline $\mathrm{FO}$ & Frontal operculum \\
\hline FOC & Frontal orbital cortex \\
\hline FP & Frontal pole \\
\hline $\mathrm{H}$ & Heschl's gyrus \\
\hline INS & Insula \\
\hline JPL & Juxtaparacentral lobule \\
\hline LG & Lingual gyrus \\
\hline $\mathrm{OP}$ & Occipital pole \\
\hline $\mathrm{OF}$ & Occipital fusiform gyrus \\
\hline OLi & Lateral occipital cortex, inferior \\
\hline OLs & Lateral occipital cortex, superior \\
\hline PAC & Paracingulate cortex \\
\hline PCN & Precuneus \\
\hline $\mathrm{PHa}$ & Parahippocampal gyrus, anterior \\
\hline PHp & Parahippocampal gyrus, posterior \\
\hline $\mathrm{PO}$ & Parietal operculum \\
\hline POG & Postcentral gyrus \\
\hline PP & Planum polare \\
\hline PRG & Precentral gyrus \\
\hline PT & Planum temporale \\
\hline SC & Subcallosal cortex \\
\hline SCLC & Supracalcarine cortex \\
\hline SGa & Supramarginal gyrus, anterior \\
\hline SGp & Supramarginal gyrus, posterior \\
\hline SPL & Superior parietal lobule \\
\hline T1a & Superior temporal gyrus, anterior \\
\hline T1p & Superior temporal gyrus, posterior \\
\hline $\mathrm{T} 2 \mathrm{a}$ & Middle temporal gyrus, anterior \\
\hline $\mathrm{T} 2 \mathrm{p}$ & Middle temporal gyrus, posterior \\
\hline T3a & Inferior temporal gyrus, anterior \\
\hline T3p & Inferior temporal gyrus, posterior \\
\hline $\mathrm{TFa}$ & Temporal fusiform, anterior \\
\hline TFp & Temporal fusiform, posterior \\
\hline TO2 & Middle temporal gyrus, temporooccipital \\
\hline TO3 & Inferior temporal gyrus, temporooccipital \\
\hline TOF & Temporooccipital fusiform gyrus \\
\hline $\mathrm{TP}$ & Temporal pole \\
\hline
\end{tabular}

specificity of the findings to language related regions, these regions were assessed without concern to the significance of the overall GLM model so as not to bias the analyses toward a conclusion of greater language regional specificity.

\section{Results}

Maps of cortical asymmetry measures by parcellation unit are presented for lateral cortex in the Figure, color-coded based on asymmetry values. Medial, inferior, superior, and temporal surface and operculum views are not shown. 


\section{Autistic Boys}
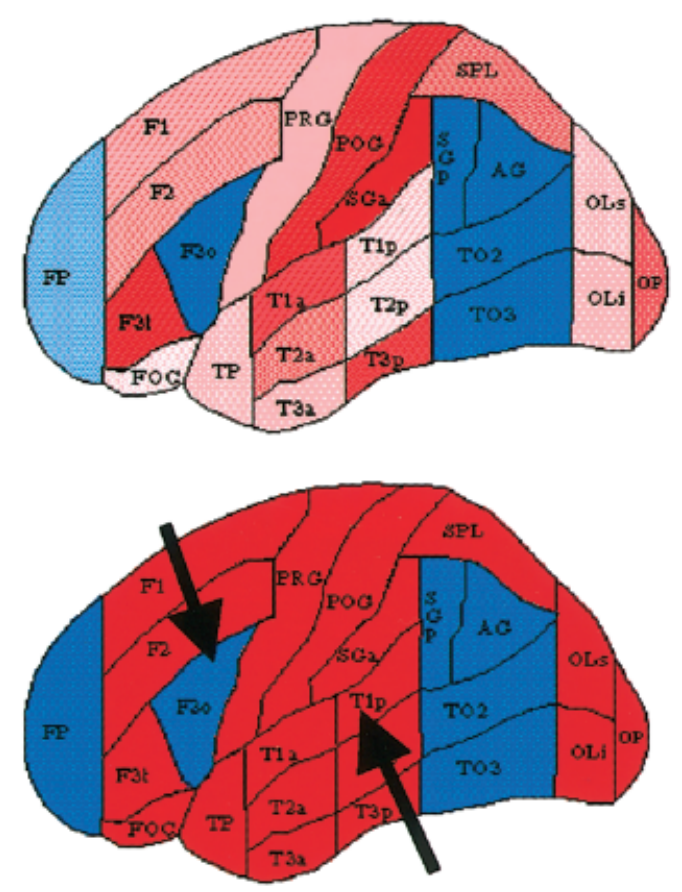

\section{Normal Boys}
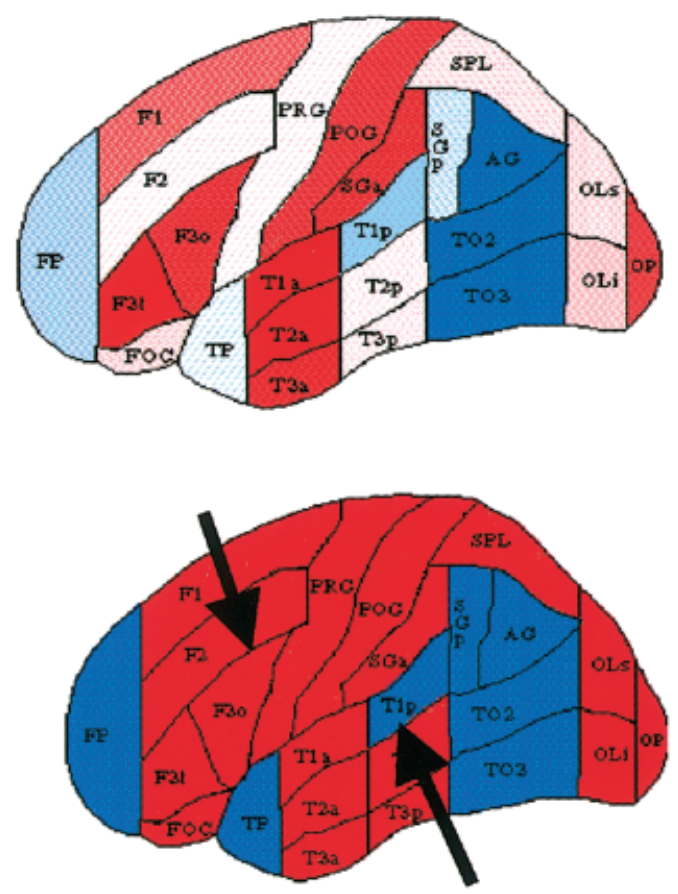

Fig. Maps of asymmetry of cortical parcellation units of the lateral view of the cerebral hemispheres in autistic boys (left) and normal control boys (right). Inferior, medial, and opercular surfaces are not shown. For all images, red indicates greater volume in the left-sided region, and blue indicates a greater right-sided regional asymmetry. The top row displays cortical asymmetry in shaded display, with color saturation proportional to asymmetry intensity (full saturation represents $>20 \%$ asymmetry). The bottom row binarizes the results, showing asymmetry direction only. Arrows indicate language-related cortical regions in frontal and temporal lobes. Autistic subjects show rightward asymmetry in frontal pars opercularum and leftward asymmetry in posterior superior temporal gyrus, reversed from that in control group. Frontal language regional asymmetry differences were significant between boys with autism and control boys $(\mathrm{p}=0.02)$. See Table 1 for parcellation unit abbreviations.

A Wilks $\lambda$ multivariate test showed that significant differences were present between control and autistic boys $(\mathrm{F}[9,19]=2.58 ; p=0.04)$ in the overall GLM model for language regions, while controlling for age and scanner. Neither covariate was significant in the model between the groups of boys: age $(\mathrm{F}[9,19]=1.1$; $p=0.41)$; scanner $(\mathrm{F}[9,19]=0.39 ; p=0.92)$. Therefore, only the significant post hoc tests comparing differences based on diagnostic groups are considered further (see Tables 1 and 2).

\section{Frontal Language Asymmetry}

In inferior lateral frontal language cortex (pars opercularis, F3o, associated with Broca's region), reversed asymmetry was observed in boys with autism compared with control boys $(\mathrm{F}[1,30]=5.58 ; p=0.02)$. This frontal language region was $27 \%$ larger on the right side in boys with autism, whereas the control boys had $17 \%$ greater volume on the left side. These differences are displayed in Table 2 and visually in the Figure.

\section{Posterior Language Asymmetry}

PT symmetry was also significantly different between control and autistic boys $(\mathrm{F}[1,30]=6.20 ; p=0.02)$, with autistics showing a $25 \%$ leftward asymmetry and controls only a $5 \%$ leftward asymmetry, as shown in Table 1. In addition, symmetry differences between autistics and control children in the posterior supramarginal gyrus (SGp) approached significance (autistics were $39 \%$ larger on the right as opposed to control children who were only $2 \%$ larger on the right $(\mathrm{F}[1,30]=3.97 ; p=0.056)$. Thus, in these two posterior language regions, the asymmetry was more extreme in autistic than in control boys. Reversed asymmetry also was observed in posterior superior temporal cortex ( $\mathrm{T} 1 \mathrm{p}$ in the Fig), associated with Wernicke's area (although with reversed polarity from the frontal language region). However, these differences were much less extreme than for the frontal pars opercularis region and were not significantly different between groups (boys with autism were $4 \%$ 
Table 2. Regional Symmetry Index Values for A Priori Analyzed Frontal Pars Opercularis (Broca) and Neighboring Frontal Language Regions, and for Posterior Superior Temporal (Wernicke) and Associated Posterior Language Regions (mean \pm SD)

\begin{tabular}{|c|c|c|c|}
\hline Region & Autistic Boys ${ }^{\mathrm{a}}$ & Control Boys ${ }^{\mathrm{a}}$ & $\begin{array}{l}\text { Autism vs Control, } \\
\mathrm{F} ; p, \mathrm{df}=(1,30)\end{array}$ \\
\hline \multicolumn{4}{|l|}{ A priori frontal language } \\
\hline F3o (pars opercularis) & $\mathrm{R}: 27 \% \pm 42$ & $\mathrm{~L}: 17 \% \pm 40$ & $5.58 ; 0.02$ \\
\hline INS (insula) & $\mathrm{L}: 5 \pm 10$ & $\mathrm{~L}: 1 \pm 6$ & $2.90 ; 0.10$ \\
\hline F3t (pars triangularis) & $\mathrm{L}: 18 \pm 40$ & $\mathrm{~L}: 33 \pm 35$ & $2.70 ; 0.11$ \\
\hline FO (frontal operculum) & $\mathrm{L}: 3 \pm 35$ & $\mathrm{~L}: 18 \pm 24$ & $0.44 ; 0.51$ \\
\hline \multicolumn{4}{|l|}{ A priori posterior language } \\
\hline PT (planum temporale) & $\mathrm{L}: 25 \pm 36$ & $\mathrm{~L}: 5 \pm 22$ & $6.20 ; 0.02$ \\
\hline SGp (posterior supramarginal gyrus) & $\mathrm{R}: 39 \pm 67$ & $\mathrm{R}: 2 \pm 42$ & $3.97 ; 0.056$ \\
\hline SGa (anterior supramarginal gyrus) & L: $33 \pm 42$ & $\mathrm{~L}: 17 \pm 50$ & $2.32 ; 0.14$ \\
\hline T1p (posterior STG) & $\mathrm{L}: 4 \pm 40$ & $\mathrm{R}: 6 \pm 21$ & $1.77 ; 0.19$ \\
\hline AG (angular gyrus) & $\mathrm{R}: 29 \pm 46$ & $\mathrm{R}: 45 \pm 59$ & $1.38 ; 0.25$ \\
\hline PO (parietal operculum) & $\mathrm{L}: 17 \pm 42$ & $\mathrm{~L}: 2 \pm 52$ & $0.48 ; 0.49$ \\
\hline
\end{tabular}

For the overall general linear model analysis with age and scanner as covariates, the Wilks' $\lambda$ multivariate test indicated that significant regional differences were present between autistic and control boys $(\mathrm{F}[9,19]=2.58 ; p=0.04)$. The regions included in the general linear model analysis and individual comparisons are shown.

${ }^{a}$ Greater volume on the right or left is indicated.

$\mathrm{SD}=$ standard deviation; $\mathrm{R}=$ right; $\mathrm{L}=$ left; $\mathrm{STG}=$ superior temporal gyrus.

greater left-sided, control boys $6 \%$ greater on the right; Table 2).

\section{Post Hoc Exploratory Analyses}

Comparisons were performed between autistic and control boys on all 39 remaining cortical parcellation units to determine whether asymmetry differences were specific to language-related regions or whether they were more pervasive. Although the multivariate tests were not significant for these 39 regions, this was an exploratory analysis assessing specificity of language findings, and therefore significant regional differences within the GLM model were explored and reported here. Only one post hoc region had significant asymmetry differences between autistic and control boys: posterior temporal fusiform gyrus, which was $20 \%$ larger on the left in autistic subjects and 6\% larger on the left in control boys $(\mathrm{F}[1,30]=6.19 ; p=0.02)$, as shown in Table 3. Trends were observed in two adja-

Table 3. Regional Symmetry Index Values for Post Hoc Analyzed Exploratory Regions Ranked to p values $<0.10$ for Differences between Autistic and Control Boys

\begin{tabular}{llll}
$\begin{array}{l}\text { Post Hoc } \\
\text { Regions }\end{array}$ & $\begin{array}{c}\text { Autistic } \\
\text { Boys }\end{array}$ & $\begin{array}{c}\text { Control } \\
\text { Boys }\end{array}$ & $\begin{array}{c}\text { Autism vs Control; } \\
\text { F; } p \text {, df }=(1,30)\end{array}$ \\
\hline TFp & L: $20 \pm 38$ & L: $6 \pm 12$ & $6.19 ; 0.02$ \\
TO3 & R: $56 \pm 37$ & R: $21 \pm 41$ & $3.91 ; 0.058$ \\
TOF & R: $31 \pm 42$ & R: $5 \pm 36$ & $3.13 ; 0.09$ \\
FMC & L: $7 \pm 19$ & R: $5 \pm 25$ & $2.91 ; 0.10$ \\
\hline
\end{tabular}

All post hoc regions not in table had $p$ values $>0.10$ between autistic and control boys.

$\mathrm{TFp}=$ temporal fusiform, posterior; $\mathrm{TO} 3=$ inferior temporal gyrus, temporooccipital; $\mathrm{TOF}=$ temporooccipital fusiform gyrus; $\mathrm{FMC}=$ frontal medial cortex. cent regions. Posterior (temporooccipital) inferior temporal gyrus (TO3) had 56\% rightward asymmetry in autistics compared with $21 \%$ larger volume on the right in control boys $(\mathrm{F}[1,30]=3.91 ; p=0.058)$. The adjacent fusiform gyrus (TOF) also showed a trend toward asymmetry differences $(31 \%$ rightward asymmetry in autistics, 5\% rightward in control boys $(\mathrm{F}[1,30]=3.13 ; p=0.09)$. The only other region showing a trend $(p=0.10)$ between groups of boys was frontal medial cortex (leftward $7 \%$ in autistics, rightward $5 \%$ in control boys, $\mathrm{F}=2.91 ; p=0.10$ ).

\section{Discussion}

This study is, to our knowledge, the first to identify specific abnormalities of structural brain volumes in regions associated with language functioning in autism. Although both frontal (Broca) and temporal (Wernicke) language-related heteromodal association cortex regions displayed a reversal of asymmetry in boys with autism compared with normal control boys, the frontal abnormality was substantially more extreme, and these differences were statistically significant. A prior single photon emission computed tomography (SPECT) study reported reversal of regional cerebral blood flow asymmetry in frontal language regions in autistic children compared with controls, ${ }^{43}$ consistent with the structural observation of this study. In addition, a prior positron emission tomography (PET) report observed reversed hemispheric dominance during verbal auditory stimulation in high-functioning autistic adults compared with control subjects. ${ }^{44}$ These asymmetry reversals in language-related SPECT and PET regional cerebral blood flow studies complement the frontal 
language cortex structural asymmetry reversal reported in this study.

MRI studies of handedness and language dominance have indicated larger size in left hemisphere cortical language regions in right-handed, left-hemisphere language dominant normal subjects. ${ }^{45-48}$ Frontal pars opercularis (Broca) was specifically correlated with handedness in normal subjects, larger on the right in left-handed subjects and larger on the left in righthanders, ${ }^{26}$ as was observed in predominantly righthanded normal boys in this study. Although this study included one left-handed and one mixed-dominant control boy, the impact of this would be expected to diminish the asymmetry differences observed if only strongly right-handed subjects had been included as controls in our study.

Prior MRI studies of subjects with SLI have reported abnormal hemispheric asymmetries in language cortexrelated measures compared with controls, ${ }^{27,28,31,32,49}$ consistent with our study findings in autism. Furthermore, the language abnormalities observed in autism share many features with those observed in SLI, and these disorders may be co-occurring or overlapping in many respects. ${ }^{18,50}$ The similarity of these neuroanatomical asymmetry abnormalities in language cortex regions in these two disorders further supports a link between autism and SLI. Parents and siblings of SLI children also displayed abnormal MRI asymmetry patterns, ${ }^{30}$ and SLI children displayed abnormal electroencephalogram asymmetries in temporal lobe electrodes in response to a semantic task. ${ }^{51}$ Future autism research may be warranted in these domains to test whether the abnormal MRI language cortex asymmetry observation in this report also is observed in family members of children with autism and whether semantic tasks produce electroencephalogram neurophysiological asymmetry abnormalities in autistic subjects.

Posterior language regions that showed asymmetry differences between autistic and control boys included planum temporale $(p=0.02)$, whereas posterior supramarginal gyrus bordered on significance $(p=$ $0.056)$. These regions had increased asymmetry in autistic compared with control boys, with PT larger on the left and posterior supramarginal gyrus (SGp) larger on the right in both groups. A similar pattern also was reported in an MRI study in language-disordered subjects, again suggesting a link between autism and language impairment. Language-disordered subjects also had increased asymmetry compared with controls in perisylvian regions, greater on the left in temporal bank (proximity of PT) and greater on the right in parietal bank (proximity of SGp). ${ }^{28}$ The planum temporale is integral to auditory processing and receptive language, and its role and network of connections in this regard are being elucidated. ${ }^{52,53}$ Reports of planum temporale asymmetry in language-disordered groups have had in- consistent results, with studies indicating increased leftward PT asymmetry in dyslexic adults, ${ }^{54}$ rightward PT asymmetry in SLI children, ${ }^{27}$ lack of PT asymmetry in dyslexic children, ${ }^{55}$ or PT asymmetry no different from normal. ${ }^{32,56-58}$ Possible reasons for these inconsistencies include heterogeneity of language-disordered subjects in these studies, differences in anatomical methods, ${ }^{59,60}$ and high interindividual variability.

Impairments in language and communication are among the core features of autism. ${ }^{1}$ Even in highfunctioning verbal autistic adults, deficits in social communication remain, though they may be more subtle than in much younger or more impaired individuals. Reviews of studies on the nature of the language problems in autism consistently point to specific areas of dysfunction: problems with pragmatic functioning (using language appropriately in social contexts; accommodating language to the needs of the listener); high-level semantic aspects of language, and problems with the use of prosody or intonation to convey meaning. ${ }^{61-64}$

Several $\mathrm{PET}^{65}$ and functional MRI ${ }^{66,67}$ studies, as well as our own functional MRI preliminary data, ${ }^{68}$ have been consistent in identifying a lateral portion of left inferior prefrontal cortex as a site activated by the processing of verbal stimuli at semantic (deep) compared with perceptual (shallow) levels of encoding in young, healthy individuals. This region is consistent with the frontal pars opercularis region that demonstrated asymmetry reversal in autism in this study. It has been hypothesized that this area may subserve semantic processes that are active when normal individuals encode verbal information for meaning. Our preliminary functional MRI data indicate that individuals with autism may utilize other brain regions rather than left inferior prefrontal cortex in this semantic encoding task, ${ }^{68}$ consistent with the abnormal structural asymmetry reversal demonstrated in this region in this study. Similarly, high-functioning autistic adults demonstrated reversed hemispheric dominance during verbal auditory stimulation observed with PET. ${ }^{44}$

The only non-language-related region that presented abnormal asymmetry in post hoc assessment between groups of boys was the posterior temporal fusiform gyrus. The adjacent temporooccipital portion of the inferior temporal gyrus and the adjacent temporooccipital fusiform gyrus also had trends toward asymmetry differences between autistic and control boys. The asymmetry in these three inferior temporal lobe regions was more extreme in the autistic subjects than in the control boys.

Subjects with autism display deficits in processing social context information from social attribution tasks and from faces. ${ }^{69,70}$ Several recent functional imaging studies have identified the fusiform gyrus and adjacent inferior temporooccipital region as important in pro- 
cessing faces. ${ }^{71-73}$ In studies of face processing by autistic or Asperger's subjects compared with control subjects, the fusiform gyrus displayed decreased activation and adjacent inferior temporooccipital cortex also demonstrated abnormally localized functional activation in autistic/Asperger's subjects, ${ }^{71,73,74}$ suggesting that the observation in this study of structural asymmetry abnormalities in these regions may be associated with significant functional and behavioral consequences. Thus, this finding of structural laterality abnormalities in ventral temporooccipital cortex regions, together with prior functional imaging studies that demonstrated abnormalities in autistic subjects in these regions related to facial processing, points toward a neuroanatomical basis for the social dysfunction in autism.

Cortical asymmetry is caused by morphometrically discernable interhemispheric volume differences that derive from differences at the tissue level. ${ }^{75}$ The tissue differences are poorly understood at this time. ${ }^{76-78}$ Cortical asymmetry may be related to differences in neuron number or neuron packing density, and such differences may occur in specific subtypes of neurons or neurons more generally. Alterations in other components of cortex also may lead to volume differences detectable by MRI morphometry. Characterizing such alterations at the tissue level eventually may help to understand the basis for the lateralization of neural processing associated with some brain asymmetries, and for the functional abnormalities associated with alterations of these asymmetry patterns. Morphometric analyses such as this study can help to point toward brain regions for which more intensive study of such tissue-based differences may prove most fruitful.

One shortcoming of this report was that only male subjects were included, and so we are not able to extrapolate these findings to female autistic subjects without further study. This is particularly pertinent in the cortical language regions investigated in this study, because there may be gender differences in normal subjects in these regions as well. ${ }^{79,80}$

This work was supported in part by grants NS02126 (M.R.H.), Cure Autism Now Foundation (M.R.H.), NS20489 (I. Rapin), Armenise Foundation Fund (V.S.C.), Fairway Trust (V.S.C. and D.K.), NS34189 (D.K.), DA09467 (D.K.), NS27950 (N.M.), P01DC03610 (part of the NICHD/NIDCD funded Collaborative Programs of Excellence in Autism; H.T.F., G.J.H.), MH57180 (N.L.), and NS37483 (N.L.).

We gratefully acknowledge I. Rapin for her review and comments on the manuscript, and P. A. Filipek for her role in image segmentation and data collection. In addition, we thank the following investigators who participated in subject recruitment and assessments, and in behavioral data analysis: D. A. Allen, M. Dunn, D. Fein, C. Feinstein, P. A. Filipek, J. Flax, I. Rapin, R. Morris, and L. Waterhouse.

\section{References}

1. APA. Diagnostic and statistical manual of mental disorders. 4th ed. Washington, DC: American Psychiatric Association, 1994.

2. Bailey A, Phillips W, Rutter M. Autism: toward an integration of clinical, genetic, neuropsychological, and neurobiological perspectives. J Child Psychol Psychiatry 1996;37:89-126.

3. Deb S, Thompson B. Neuroimaging in autism. Br J Psychiatry 1998; 173:299-302.

4. Minshew NJ, Dombrowski SM. In vivo neuroantomy of autism: neuroimaging studies. In: Bauman ML, Kemper TL, eds. The neurobiology of autism. Baltimore: Johns Hopkins University Press, 1994:66-86.

5. Jacobson R, Le Couter A, Howlin P, Rutter M. Selective subcortical abnormalities in autism. Psychol Med 1988;18:39-48.

6. Sears LL, Vest C, Mohamed S, et al. An MRI study of the basal ganglia in autism. Prog Neuropsychopharmacol Biol Psychiatry 1999;23:613-624.

7. Schaefer GB, Thompson JN, Bodensteiner JB, et al. Hypoplasia of the cerebellar vermis in neurogenetic syndromes. Ann Neurol 1996;39:382-385.

8. Piven J, Arndt S. The cerebellum and autism. Neurology 1995; 45:398-402.

9. Courchesne E, Townsend J, Saitoh O. The brain in infantile autism: posterior fossa structures are abnormal. Neurology 1994;44:214-223.

10. Rapin I. Preschool children with inadequate communication: developmental language disorder, autism, low IQ. London: Mac Keith Press, 1996.

11. Courchesne E, Karns CM, Davis HR, et al. Unusual brain growth patterns in early life in patients with autistic disorder: an MRI study. Neurology 2001;57:245-254.

12. Kanner L. Autistic disturbances of affective contact. Nervous Child 1943;2:217-250.

13. Kemper TL. Neuroaantomic studies of dyslexia and autism. In: Swann JW, Messer A, eds. Disorders of the developing nervous system: changing views of their origin, diagnosis and treatment. New York: Liss, 1988.

14. Lainhart JE, Piven J, Wzorek M, et al. Macrocephaly in children and adults with autism. J Am Acad Child Adolesc Psychiatry 1997;36:282-290.

15. Piven J, Arndt S, Bailey J, et al. An MRI study of brain size in autism. Am J Psychiatry 1995;152:1145-1149.

16. Filipek PA, Richelme C, Kennedy DN, et al. Morphometric analysis of the brain in developmental language disorders and autism. Ann Neurol 1992;32:475 (Abstract).

17. Ventner A, Lord C, Schopler E. A follow-up study of highfunctioning autistic children. J Child Psychol Psychiatry 1992; 33:489-507.

18. Kjelgaard M, Tager-Flusberg H. An investigation of language impairment in autism: implications for genetic subgroups. Lang Cogn Processes 2001;16:287-308.

19. Barrett S, Beck JC, Bernier R. An autosomal genomic screen for autism. Collaborative linkage study of autism. Am J Med Genet 1999;88:609-615.

20. Bradford Y, Haines J, Hutcheson H, et al. Incorporating language phenotypes strengthens evidence of linkage to autism. Am J Med Genet 2001;105:539-547.

21. Folstein SE, Mankoski RE. Chromosome 7q: where autism meets language disorder? Am J Hum Genet 2000;67:278-281.

22. International. Molecular Genetic Study of Autism Consortium. A full genome screen for autism with evidence for linkage to a region on chromosome 7q. Hum Mol Genet 1998;7:571-578.

23. Lai CS, Fisher S, Hurst JA. The speech region on human 7q.31: genomic characterization of the critical interval and localization of translocations associated with speech and language disorder. Am J Hum Genet 2000;67:357-368. 
24. Wassink TH, Piven J, Vieland VJ, et al. Evidence supporting WNT2 as an autism susceptibility gene. Am J Med Genet 2001;105:406-413.

25. Clark MM, Plante E. Morphology of the inferior frontal gyrus in developmentally language-disordered adults. Brain Lang 1998;61:288-303.

26. Foundas AL, Eure KF, Luevano LF, Weinberger DR. MRI asymmetries of Broca's area: the pars triangularis and pars opercularis. Brain Lang 1998;64:282-296.

27. Gauger LM, Lombardino LJ, Leonard CM. Brain morphology in children with specific language impairment. J Speech Lang Hear Res 1997; 40:1272-1284.

28. Leonard CM, Voeller KK, Lombardino LJ, et al. Anomalous cerebral structure in dyslexia revealed with magnetic resonance imaging. Arch Neurol 1993;50:461-469.

29. Leonard C, Lombardino LJ, Mercado LR, et al. Cerebral asymmetry and cognitive development in children: a magnetic resonance imaging study. Psychol Sci 1996;7:79-85.

30. Plante E. MRI findings in the parents and siblings of specifically language-impaired boys. Brain Lang 1991;41:67-80.

31. Plante E, Swisher L, Vance R, Rapcsak S. MRI findings in boys with specific language impairment. Brain Lang 1991;41:52-66.

32. Robichon F, Levrier O, Farnarier P, Habib M. Developmental dyslexia: atypical cortical asymmetries and functional significance. Eur J Neurol 2000;7:35-46.

33. Caviness VS, Kennedy DN, Richelme C, et al. The human brain age 7-11 years: a volumetric analysis based on magnetic resonance images. Cereb Cortex 1996;6:726-736.

34. Filipek PA, Kennedy DN, Pitcher DA, Caviness VS. MRIbased morphometric analyses: reproducibility across multiple systems and pulse sequences over time on a single volunteer. Proc Soc Magn Reson Med 1991;10:753.

35. Worth AJ, Makris M, Meyer JW, et al. Semiautomatic segmentation of brain exterior in magnetic resonance images driven by empirical procedures and anatomical knowledge. Med Image Anal 1988;2:315-324.

36. Filipek PA, Richelme C, Kennedy DN, Caviness VS. The young adult human brain: an MRI-based morphometric analysis. Cereb Cortex 1994;4:344-360.

37. Filipek PA, Kennedy DN, Caviness VS. A method of morphometric analysis of the human brain based upon magnetic resonance imaging. Ann Neurol 1988;24:356.

38. Kennedy DN, Filipek PA, Caviness VS. Anatomic segmentation and volumetric calculations in nuclear magnetic resonance imaging. IEEE Trans Med Imag 1989;8:1-7.

39. Kennedy DN, Lange N, Makris N, et al. Gyri of the human neocortex: an MRI-based analysis of volume variance. Cereb Cortex 1998;8:372-384.

40. Galaburda AM, Rosen GD, Sherman GF. Individual variability in cortical organization: its relationship to brain laterality and implications for function. Neuropsychologica 1987;28: 529-546.

41. Caplan D, Gow D, Makris N. Analysis of lesions by MRI in stroke patients with acoustic-phonetic processing deficits. Neurology 1995;45:293-298.

42. Caplan D, Hildebrandt N, Makris N. Location of lesions in stroke patients with deficits in syntactic processing in sentence comprehension. Brain 1996;119:933-949.

43. Chiron C, Leboyer M, Leon F, et al. SPECT of the brain in childhood autism: evidence for a lack of normal hemispheric asymmetry. Dev Med Child Neurol 1995;37:849-860.

44. Muller RA, Behen ME, Rothermel RD, et al. Brain mapping of language and auditory perception in high-functioning autistic adults: a PET study. J Autism Develop Dis 1999;29:19-31.

45. Foundas AL, Leonard CM, Gilmore R, et al. Planum temporale asymmetry and language dominance. Neuropsychologia 1994; 32:1225-1231.
46. Foundas AL, Leonard CM, Heilman KM. Morphologic cerebral asymmetries and handedness. The pars triangularis and planum temporale. Arch Neurol 1995;52:501-508.

47. Foundas AL, Leonard CM, Gilmore RL, et al. Pars triangularis asymmetry and language dominance. Proc Natl Acad Sci USA 1996;93:719-722.

48. Steinmetz H, Volkmann J, Jancke L, Freund HJ. Anatomical left-right asymmetry of language-related temporal cortex is different in left- and right-handers. Ann Neurol 1991;29: 315-319.

49. Jernigan TL, Hesselink JR, Sowell E, Tallal PA. Cerebral structure on magnetic resonance imaging in language- and learningimpaired children. Arch Neurol 1991;48:539-545.

50. Tager-Flusberg H. Language impairments in children with complex neurodevelopmental disorders. In: Levy Y, Schaeffer J, eds. Toward a definition of specific language impairment. Mahwah, NJ: Erlbaum, 2002.

51. Shafer VL, Schwartz RG, Morr ML, et al. Deviant neurophysiological asymmetry in children with language impairment. Neuroreport 2000;11:3715-3718.

52. Papathanassiou D, Etard O, Mellet E, et al. A common language network for comprehension and production: a contribution to the definition of language epicenters with PET. Neuroimage 2000;11:347-357.

53. Nakada T, Fujii Y, Yoneoka Y, Kwee IL. Planum temporale: where spoken and written language meet. Eur Neurol 2001;46: 121-125.

54. Leonard CM, Eckert MA, Lombardino LJ, et al. Anatomical risk factors for phonological dyslexia. Cereb Cortex 2001;11: $148-157$.

55. Larsen JP, Hoien T, Lundberg I, Odegaard H. MRI evaluation of the size and symmetry of the planum temporale in adolescents with developmental dyslexia. Brain Lang 1990;39: 289-301.

56. Preis S, Jancke L, Schittler P, et al. Normal intrasylvian anatomical asymmetry in children with developmental language disorder. Neuropsychologia 1998;36:849-855.

57. Heiervang E, Hugdahl K, Steinmetz H, et al. Planum temporale, planum parietale and dichotic listening in dyslexia. Neuropsychologia 2000;38:1704-1713.

58. Rumsey JM, Donohue BC, Brady DR, et al. A magnetic resonance imaging study of planum temporale asymmetry in men with developmental dyslexia. Arch Neurol 1997;54:1481-1489.

59. Shapleske J, Rossell SL, Woodruff PW, David AS. The planum temporale: a systematic, quantitative review of its structural, functional and clinical significance. Brain 1999;29:26-49.

60. Zetzsche T, Meisenzahl EM, Preuss UW, et al. In-vivo analysis of the human planum temporale (PT): does the definition of PT borders influence the results with regard to cerebral asymmetry and correlation with handedness? Psychiatry 2001;107: 99-115.

61. Paul R. Communication. In: Cohen DJ, Donnellan AM, eds. Handbook of autism and pervasive developmental disorders. New York: Wiley, 1987.

62. Tager-Flusberg H. A psycholinguistic perspective on language development in the autistic child. In: Dawson G, eds. Autism: new directions in diagnosis, nature, and treatment. New York: Guilford, 1989.

63. Tager-Flusberg H. What language reveals about the understanding of minds in children with autism. In: Baron-Cohen S, Tager-Flusberg H, Cohen DJ, eds. Understanding other minds: perspectives from autism. Oxford: Oxford University Press, 1993. 
64. Tager-Flusberg H. The role of theory of mind in language acquisition: contributions from the study of autism. In: Adamson L, Romski MA, eds. Research on communication and language disorders: contributions to theories of language development. Baltimore: Paul Brookes Publishing, 1997.

65. Kapur S, Craik FI, Tulving E, et al. Neuroanatomical correlates of encoding in episodic memory: levels of processing effect. Proc Natl Acad Sci USA 1994;91:2008-2011.

66. Poldrack RA, Wagner AD, Prull MW, et al. Functional specialization for semantic and phonological processing in the left inferior prefrontal cortex. Neuroimage 1999;10:15-35.

67. Demb JB, Desmond JE, Wagner AD, et al. Semantic encoding and retrieval in the left inferior prefrontal cortex: a functional MRI study of task difficulty and process specificity. J Neurosci 1995; 15:5870-5878.

68. Steele S, Clark JA, Chabris CF, et al. Semantic vs nonsemantic word activation in autistic vs controls. International Meeting for Autism Research; 2001; San Diego, CA.

69. Adolphs R, Sears L, Piven J. Abnormal processing of social information from faces in autism. J Cog Neurosci 2001;13: 232-240.

70. Klin A. Attributing social meaning to ambiguous visual stimuli in higher-functioning autism and Asperger syndrome: The Social Attribution Task. J Child Psychol Psychiatry 2000;41: 831-846.

71. Critchley HD, Daly EM, Bullmore ET, et al. The functional neuroanatomy of social behavior: changes in cerebral blood flow when people with autistic disorder process facial expressions. Brain 2000;123:2203-2212.
72. Kanwisher N, McDermott J, Chun MM. The fusiform face area: a module in human extrastriate cortex specialized for face perception. J Neurosci 1997;17:4302-4311.

73. Schultz RT, Gauthier I, Klin A, et al. Abnormal ventral temporal cortical activity during face discrimination among individuals with autism and Asperger's syndrome. Arch Gen Psychiatry 2000;57:331-340.

74. Pierce K, Muller RA, Ambrose J, et al. Face processing occurs outside the fusiform "face area" in autism: evidence from functional MRI. Brain 2001;124:2059-2073.

75. Caviness VS, Lange N, Makris N, et al. MRI-based brain volumetrics: emergence of a developmental brain science. Brain Dev 1999;21:289-295.

76. Rosen GD. Cellular, morphometric, ontogenetic and connectional substrates of anatomical asymmetry. Neurosci Biobehav Rev 1996;20:607-615.

77. Best CT. The emergence of cerebral asymmetries in early human development: a literature review and a neuroembryological model. In: Molfese DL, Segalowitz SJ, eds. Brain lateralization in children: developmental implications. New York: Guilford Press, 1988.

78. Chi JG, Dooling EC, Gilles FH. Left-right asymmetries of the temporal speech areas of the human fetus. Arch Neurol 1977; 34:346-348.

79. Shaywitz BA, Shaywitz SE, Pugh KR, et al. Sex differences in the functional organization of the brain for language. Nature 1995;373:607-609.

80. Schlaepfer TE, Harris GJ, Tien AY, et al. Structural differences in the cerebral cortex of healthy female and male subjects: a magnetic resonance imaging study. Psychiatry Res 1995;61: 129-135. 